\title{
The uses and abuses of mathematics in early modern philosophy: introduction
}

\author{
Tamás Demeter ${ }^{1} \cdot$ Eric Schliesser ${ }^{1,2}$
}

Received: 21 December 2017 / Accepted: 26 December 2017 / Published online: 16 January 2018 (C) Springer Science+Business Media B.V., part of Springer Nature 2018

Although in modern science mathematization is an unquestionable ideal, this status was far from being unequivocal in early modern philosophy. There were clear tendencies, especially following the widespread reception of Newton's Principia, toward the mathematization of all fields of knowledge from natural philosophy through medicine to moral philosophy. These tendencies manifested in various forms of taking mathematics as the epistemic ideal to be adopted in any given field. So, mathematizing zeal was discernible beyond the borders of natural philosophy: it is enough to remind the reader of Archibald Pitcairne's and George Cheyne's aspirations to mathematize medicine, ${ }^{1}$ of Craig's (1699) mathematical principles of christian theology, and also of Hutcheson's (1725) attempt to formulate a mathematical canon for moral philosophy - which was later criticized by Reid (1748) on account of trying to quantify the unquantifiable.

There were also strong voices that drove away from mathematization and emphasized the inability of mathematics to deal with the variety of phenomena, to represent nature adequately, as well as its moral and epistemic shortcomings that prevent it from being an epistemic ideal. In what follows, we use 'anti-mathematicism' and its cognates to refer to criticism(s) of the application of (some) mathematics. ${ }^{2}$ The heritage of these early modern debates surrounding mathematics and mathematization

\footnotetext{
1 On Pitcairne's and Cheyne's aspirations see Guerrini (1987, 1989).

${ }^{2}$ For more details on this terminology and historical context see Chapter 13 of Schliesser (2017) and Schliesser (2018).
}

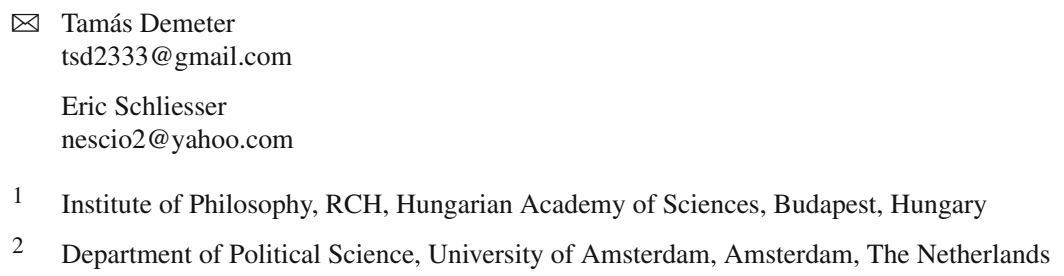


has been present in the subsequent history of the sciences and the heritage is still with us even today. Hannes Leitgeb's diagnosis of certain contemporary tendencies also apply to many of these early modern developments: "critics of mathematization of (parts of) philosophy do not so much put forward arguments as really express a feeling of uneasiness or insecurity vis-à-vis mathematical philosophy." (Leitgeb 2013: p. 271)

The primary focus of this special issue is to unfold the philosophical roots and manifestations of this uneasiness in the early modern period, and explore the discontents and reservations that were formulated as epistemological, methodological and moral considerations. Another focus is on those commitments and attitudes to the value of a mathematical approach that became explicit in various practices of knowledge production. And the third focus is on exploring some of those cases where the authority of mathematics is exploited or undermined in the service of some hidden epistemic or non-epistemic purpose.

One obvious but rarely confessed root of anti-mathematicist sentiment could be a lack of competence in mathematics. Antagonists of mathematization are frequently those unqualified in mathematics, and not being well-versed in mathematics brings along the uneasiness and incomprehensibility of those fields where it is extensively applied. This might serve as a sufficient drive to advance a case against the deployment of mathematics anywhere beyond its obvious sphere of authority, i.e. the pure relations of numbers and figures. Sometimes, a critical attitude toward Newton and/or various applications of mathematics was taken as one bit of evidence of lack of competence.

So, for example, there has been a persistent strain of criticism of David Hume that has insinuated that he simply did not understand Newton or lacked mathematical competence. ${ }^{3}$ But when Hume (or any other historical figure) deviates from Newton this need not entail lack of understanding, it can, depending on other evidence, also be taken as informed criticism. ${ }^{4}$ In Hume's case, critical scholars also draw on a (1772) letter to William Strahan in which he mentions a 1755 draft essay "On the Metaphysical Principles of Geometry" that he withdrew upon the advice of his friend the mathematician Lord Stanhope, "who convinced me that either there was some defeat in the argument or in its perspicuity." 5 This remark is taken as evidence of Hume's acknowledged lack of competence in mathematics. But the remark could also be taken at face value and an expression of scholarly integrity: he accepted a compelling criticism.

Even so, the more interesting cases of anti-mathematicism are those where mathematical competence is not in question, yet the universal applicability of mathematics is considered limited. Among proponents of such limitations one can find translators of Newton (Buffon, who translated Method of Fluxions and infinite series in 1740, and, himself an accomplished mathematician), and practitioners of otherwise advanced mathematics (like René Descartes and Denis Diderot) as Mark Wilson's and Charles Wolfe's papers illustrates.

The philosophical motivations for putting constraints on mathematics are manifold and arise from various metaphysical and epistemological commitments. These are

\footnotetext{
3 For very different treatments, see Stein (1993) and Smith (2001).

4 See Schliesser (2011).

5 See Newman (1981).
} 
illustrated in this special issue. For example, Jon Shaheen and Alison Peterman both show that Margaret Cavendish's anti-mathematicism is at least partly motivated by her metaphysics of matter. Alan Nelson argues that Descartes's system of philosophy motivates constraints on the extension of mathematics into fields of study where its introduction is considered inappropriate. Steffen Ducheyne reminds us that Spinoza's geometrical method prompted searching analysis of its validity by Nieuwentijt and Musschenbroek among others, who argued that it does not correspond to nature. These essays show that there was a persistent questioning sometimes even an aspiration to displace the mathematical standards of intelligibility as universal epistemic standards.

Those who take mathematics as the epistemic ideal for inquiry in general do not always take it as such for metaphysical reasons, but rather for its effectiveness throughout various epistemic contexts. There are several cardinal epistemic virtues associated with mathematics, such as e.g. certainty and the intuitive clarity of its content, that make it a suitable candidate for raising it to the status of an epistemic ideal. And sometimes these virtues turn out to be directly relevant in argumentative contexts as Gábor Zemplén shows : in Newton's works mathematical idealizations and diagrams have the role of minimizing the burden of experimental proof by exploiting the epistemic authority that many of us ascribe to mathematics. One could also point out social processes driving toward the relevance of mathematical certainty and intuitive clarity in overcoming ideological sectarianism in one period, and leading to the charge of sectarianism in another-considerations that might lead to ideas concerning the social embeddedness of mathematics as a relevant element in an understanding of mathematical knowledge. ${ }^{6}$ And as Tamás Demeter argues, Hume's case illustrates that an awareness of the social character of the mathematical enterprise can lead to sceptical challenges undermining the role of mathematics as the leading epistemic ideal.

Even though mathematics is unquestionably effective in several branches of inquiry, the phenomenon that Wigner (1960) has called "the unreasonable effectiveness of mathematics in the natural sciences" is another potential source from which uneasiness about mathematics can arise. Even though there is a dominant tradition at least since Galileo that takes mathematics to be "the language of nature", how it can fulfill this role remains a mystery to many, and so it remains a source of scepticism about the thorough mathematization of nature. As this special issue illustrates, one way to characterize the history of science and philosophy in terms of attitude toward mathematics is in terms of the pendulum of mathematicism and anti-mathematicism driven by such doubts.

One can find this pendulum swinging while studying the historical landscape in both lower and higher resolution. While this special issue includes papers that individually and collectively represent a higher resolution, as they are case studies taken from a 150 -years timespan, the swings are as well visible here as with studying the history of science with a lower resolution in terms of a grand narrative. This story could lead from the mathematizing zeal of the Scientific Revolution and its immediate aftermath, through a vibrant eighteenth century anti-mathematicist inclination ${ }^{7}$ toward an alternative standard of inquiry that it found in natural history, which was not, unlike certain

\footnotetext{
6 See Schaffer (1989) for some such contexts in Britain.

7 We find strains of anti-mathematicism, in addition to Diderot, Hume, and Buffon, in Mandeville and Berkeley.
} 
branches of Romanticism, anti-science. This pendulum still swings in the twentieth century most visibly in the debates surrounding Deutsche Physik. There one can find echoes of these historical arguments from the clarity and objectivity of mathematical representations on the one hand, to the arguments that not only nature is more complex than to be an object of mathematical representation, but such an attempt reflects the distortion not only the object but also the subject of representation.

This special issue of Synthese contributes to a lively trend in contemporary history of philosophy of science. It can be conveniently read as a supplement to the recently published The Language of Nature volume (Gorham et al. 2016), which offers case studies from the seventeenth century. And the forthcoming special issue of Journal of Early Modern Studies on the mathematization of natural philosophy (ed. by Dana Jalobeanu, Grigore Vida) will be a successor. We hope that the papers presented here will prove to be valuable and lasting contributions to this lively field of research.

Acknowledgements This special issue contributes to the research programme of the MTA BTK Lendület 'Morals and Science' Research Group. Eric Schliesser's work falls under FWO Grant G061215N "The limits of formal philosophy".

\section{References}

Craig, J. (1699). In R. Nash (Eds.), John Craige's mathematical principles of Christian theology. Carbondale: Southern Illinois University Press (1991).

Gorham, G., et al. (2016). The language of nature: Reassessing the mathematization of natural philosophy in the seventeenth century. Minneapolis: University of Minnesota Press.

Guerrini, A. (1987). Archibald Pitcairne and Newtonian medicine. Medical History, 31, 70-83.

Guerrini, A. (1989). Isaac Newton, George Cheyne, and the Principia Medicinae. In R. French \& A. Wear (Eds.), The medical revolution of the seventeenth century. Cambridge: Cambridge University Press.

Hutcheson, F. (1725). In W. Leidhold (Eds.), An inquiry into the origin of our ideas of beauty and virtue. Indianapolis: Liberty Fund (2008).

Leitgeb, H. (2013). Scientific philosophy, mathematical philosophy and all that. Metaphilosophy, 44, 267275.

Newman, R. (1981). Hume on space and geometry. Hume Studies, 7, 1-31.

Reid, T. (1748). An essay on quantity. Philosophical Transactions of the Royal Society of London, 45, $505-520$.

Schaffer, S. (1989). The glorious revolution and medicine in Britain and the Netherlands. Notes and Records of the Royal Society of London, 43, 167-90.

Schliesser, E. (2011). Newton's challenge to philosophy: A programmatic essay. HOPOS: The Journal of the International Society for the History of Philosophy of Science, 1, 101-128.

Schliesser, E. (2017). Adam Smith: Systematic philosopher and public thinker. Oxford: Oxford University Press.

Schliesser, E. (2018). Four methods of empirical enquiry in the aftermath of Newton's challenge. In S. Bodenmann \& A.-L. Rey (Eds.), What does it mean to be an empiricist?. Cham: Springer.

Smith, G. E. (2001). Comments on Ernan McMullin's 'The impact of Newton's principia on the philosophy of science. Philosophy of Science, 68, 327-338.

Stein, H. (1993). On philosophy and natural philosophy in the seventeenth century. Midwest Studies in Philosophy, 18, 177-201.

Wigner, E. (1960). The unreasonable effectiveness of mathematics in the natural sciences. Communications on Pure and Applied Mathematics, 13, 1-14. 